\title{
GERONA, DE GALDÓS: EN EL ESPACIO HEROICO
}

\author{
Ermitas PENAS \\ Universidade de Santiago de Compostela \\ Grupo de Estudios Galdosianos (GREGAL)
}

\section{RESUMEN}

Este trabajo tiene por objeto el estudio del espacio en el episodio galdosiano Gerona. Desde un inicial realismo genético, el autor practica un realismo intencional creando un espacio urbano dinámico, cuando la ciudad es sitiada por los franceses, con descripciones evocadoras de alto valor metafórico y simbólico.

Palabras Clave: Galdós, episodio nacional, novela histórica realista, yo protagonista, espacio urbano, descripción, movimiento de los personajes, ciudad sitiada, ciudad hambrienta, ciudad muerta, ciudad heroica, realismo intencional.

\section{ABSTRACT}

This work analyze the novelistic space in the Galdo's episode Gerona. Starting from an initial genetic realism, the author uses an intentional realism to create a urban and dynamic space, by using evocative descriptions of a high metaforic value and symbolism, while the town is under siege by the French

Key Words: Galdós, national episode, historical realistic novel, I as protagonist, urban space, description, character's mobility, surrounded city, hungry city, dead city, heroic city, intentional realism.

El episodio que toma como título la ciudad catalana es el séptimo de la primera serie de los Episodios Nacionales. Fue publicado por Benito Pérez Galdós en 1874 (Madrid, Noguera), quien lo había escrito en junio de ese mismo año, tal como consta al final de manuscrito y de la edición princeps.

Don Benito, sitúa la acción en un medio urbano: Gerona, ciudad provinciana y amurallada, de unos 8.000 habitantes, fundada por los romanos. Pero no en un momento cualquiera de su vida, sino en uno muy concreto y 
claramente histórico: 1809, el año del tercer asedio de las tropas francesas, al que habían precedido otros dos en 1808. Es decir, este séptimo episodio nos presenta la ciudad gerundense tanto en un tiempo excepcional como en una situación espacial anómala y transgresora: la de la urbe sitiada.

Como es habitual en los Episodios Nacionales, el escritor canario, siguiendo las pautas del modelo de novela histórica realista a que se acoge (Penas, 1911), ensambla con inusitada maestría la Historia, el doloroso suceso transcurrido desde julio a diciembre protagonizado por los militares y, sobre todo, para la fama, por su tenaz gobernador, don Mateo Álvarez, y la historia menuda y civil, la del colectivo ciudadano conformado por los héroes anónimos que perdieron la vida o la conservaron en circunstancias extremas, cuyo rastro no guarda la memoria.

Como es bien conocido, Gerona no es narrada por el protagonista de la primera serie, Gabriel Araceli. Seguramente, como la crítica viene sosteniendo, Galdós para evitar la monotonía quiso cambiar la modalización -punto de vista y voz- habitual de las novelas históricas del ciclo de la Guerra de la Independencia, dando ahora relevancia a Andresillo Marijuán, a quien el lector ha conocido en Bailén. Será este quien relate a Araceli lo sucedido durante los siete meses de asedio por él vividos como un resistente más. De modo que Galdós, jugando siempre con el recurso propio de los libros de caballerías del manuscrito hallado, que Cervantes tan hábilmente parodia, propone una sofisticada, aunque verosímil, variación. Así, Gerona surge como un interludio entre Zaragoza y Cádiz, dos episodios en los que Gabriel sigue relatando, en primera persona, su vida como sujeto principal de ella y los hechos históricos en los que se vio inmerso. Sin embargo, aquí don Benito complica, como en el Quijote, la textura discursiva del episodio al presentar dos e, incluso, tres narradores. Así, la relación oral de Marijuán que hace a Araceli en una casa del Puerto de Santa María cuando este volvía de Talavera y aquel de Gerona, es convertida en un texto escrito por Gabriel - «Relación de Andresillo Marijuán-», quien utiliza también como auxiliar el manuscrito de Pablo Nomde$\mathrm{deu}^{1}-$ «Diario de las peripecias del sitio»- que Andrés había regalado el día de su boda con Siseta al protagonista de la primera serie. No obstante, Gerona es enmarcado, en su principio y final, por la narración de Araceli. Y las modificaciones estilísticas que realiza en el relato de Andrés, que puso por escrito cuando ya contaba algo más de ochenta años, se deben a que el «rudo lenguaje» y «tosco estilo» empleado por Marijuán rompían la unidad del suyo en

1. Personaje inspirado, según Miralles (2001: 200), en el real Juan Andrés Nieto, cirujano del hospital de Gerona. 
las seis novelas precedentes, puesto que -dice- «tenía empeño en uniformar todas las partes de esta historia de mi vida, de modo que en su vasta longitud se hallase el trazo de una sola pluma»².

De Gerona da su desmemoriado autor un dato de sumo interés para nuestro propósito en este trabajo y para el volumen que lo contiene en relación con el espacio urbano ${ }^{3}$, del que M. ${ }^{a}$ T. Zubiaurre (2000: 229) considera que fue la novela realista la gran creadora o iniciadora. Recordando el regreso a España de un viaje a París en 1868, que de Perpiñán lo llevaría, en coche, a Figueras y de aquí, en ferrocarril, a Gerona, escribe Galdós en su autobiografía (La Esfera, 1916): «Vi y examiné esta población a mi gusto, visitando sus monumentos y recorriendo todas sus calles y plazas» (2004: 29).

Algo parecido, pero más matizado, había dicho en El Imparcial de Murcia el 12 de agosto de 1903, tal como recoge Bastons i Vivanco (2004: 39):

De Figueras, conservo tan solo una vaga idea. En cambio, Gerona, donde pasé un día con su noche, permaneció en mi mente con impresiones indelebles. Recorrí con incansable agilidad juvenil todas sus calles, sus pintorescas inmediaciones, visité sus dos grandes iglesias, San Félix y la Catedral, encaramada sobre la ingente escalinata. Las plazas, de las Coles y del Vino, las calles Cort-Real y Ciudadanos, la cercana eminencia de Monjuich, los despedazados restos de bastiones, la mansa corriente del Cuyar, quedaron bien estampados en mi memoria.

Pero, además de constatar con estas palabras la existencia de un locus urbano percibido por su experiencia de visitante de la ciudad, el anciano don Benito limita, en su autobiografía, su plasmación artística al simple recuerdo: «Tan fijos quedaron en mi mente las bellezas, accidentes y rincones [...] que no necesité más para describirla» (2004: 29). Es decir, Galdós, que en aquel 1868 no pensaba redactar ninguna novela - « $i$ Qué lejos estaba yo de pensar que seis años después había de escribir el episodio Gerona!»(29)- parece, desde la memoria, adscribir o reducir su tarea de creador literario de ese medio urbano verídico a una simple práctica de realismo genético (Villanueva, 2004), incitado por el contacto directo con la capital de la comarca del Gironés.

No obstante, dudando de sí mismo, pero interesado en el retrato empírico y exacto de la geografía urbana pidió un croquis de la ciudad a su amigo Manuel Almeda, estudiante de arquitectura en Madrid, según revela en 1910

2. Cito y así lo haré en adelante por Troncoso (2005: 887).

3. Las presentes páginas se enmarcan en el proyecto de investigación, Edición y estudios críticos de la obra literaria de Benito Pérez Galdós (FFI210-15995), dirigido por Ermitas Penas y financiado por el Ministerio de Ciencia e Innovación 
a Enrique González Fiol (El Bachiller Corchuelo) en una conocida entrevista de Por esos mundos:

Para mi episodio me valí de un muchacho geronés que conocí en el Ateneo viejo; él con un lápiz en un papel me fue trazando el plano de las calles y yo las iba recordando como ante el plano mejor construido (48).

Don Benito acude a fuentes históricas librescas como en otros episodios $\mathrm{y}^{4}$, luego, sobre esta base verídica -fechas, sucesos, lugares, seres auténticos que entran en la trama de la novela- construye el tejido de sus ficciones verosímiles (Hinterhäuser, 1963; Gullón, 1970; Penas, 2011). Como en Trafalgar, Bailén o Zaragoza, en Gerona, el escritor canario imagina, según Montesinos (1968: 109) «grandes acciones guerreras [...] y nos las hace ver a través de sus personajes». Nunca mejor dicho en el caso que nos ocupa, pues únicamente estas llegan al lector a través de los ojos de Andresillo Marijuán. Y, por supuesto, el espacio urbano de la novela, no es ajeno a esta particular focalización, sino todo lo contrario. Es el joven soldado, natural de la Almunia de Doña Godina, quien condiciona la configuración de la topografía gerundense a través de su mirada y, además, da determinados datos sobre ella proporcionados por otros personajes cuando él, que obviamente no goza del don de la ubicuidad, carece de ellos.

Esa geografía de la ciudad, constituida por sus barrios, calles, plazas, edificios públicos, religiosos y civiles, viviendas, etc., aparece en Gerona vinculada, en principio, a la percepción que de ella tuvo Galdós cuando la visitó. De este modo, se nombran diferentes elementos, de acuerdo con la realidad de su urbanismo, asociados a determinadas acciones de los personajes y a su ubicación en este (Gullón, 1984). Así, en una casa de la calle Cort-Real habitan los cuatro hijos del difunto cerrajero Mongat y el soldado Marijuán, en cuyo piso de arriba lo hacen el médico viudo Pablo Nomdedeu y su hija enferma y sorda Josefina.

Andrés hace guardia en diferentes enclaves: el castillo de Monjuich, los reductos del Condestable y el Cabildo, y la torre de San Narciso, en la que oye, el 13 de junio de 1809, la respuesta negativa del gobernador, don Mariano Álvarez de Castro, a la rendición de la plaza. Sobre aquella y la de San Luis los franceses, que también se habían apoderado del barrio de Pedret, arrojan bombas hasta el 25, las destrozan y el 19 sus defensores tienen que abandonarlas.

En julio los cerdos -porchs les llamaban los catalanes- intentaron cuatro veces conquistar Monjuich y, aunque no lo lograron, dejaron allí dos mil

4. Miralles (2001) las ha puesto al día.

Anales, 24, 2012, pp. 163-180 
hombres entre muertos y heridos. Durante todo el mes, cambiada la táctica, pusieron su empeño en evitar la entrada de víveres en la ciudad. El 12 de agosto se rindió el castillo y por la tarde los que sobrevivieron de la guarnición fueron llevados al hospital, todo lo cual ve Andrés desde la Torre Gironella.

El 13 los franceses comenzaron a levantar baterías por todos lados, una vez que la gran fortaleza ya era suya. En pocos días muchos cañones estaban preparados contra la muralla de San Cristobal y la Puerta de Francia. Como esta era débil hubo que reforzar la defensa con parapetos, zanjas y vallas en los puntos menos resistentes, en lo que trabajaban mujeres y ancianos. También los niños que, como Badoret, Manalet y Gasparó, ayudaron a construir con barro el muro para cerrar el paso a la calle de la Barca.

Entre tanto, se esperaba un convoy con alimentos, pero no llegaba. Solo, esporádicamente, alguien conseguía entrar en Gerona con alguna vitualla. Durante el mes de agosto, como la guarnición era escasa y no eran posibles los relevos, fue necesario abrir fuego sin descanso. A Andrés, como a todos sus compañeros, no le estaba permitido dormir. El gobernador manda poner dos cañones en el tejado de la catedral de Santa María donde se suben los chicos para verlos.

La familia Mongat, sinécdoque de los habitantes de la ciudad, no come ya alimentos habituales: comienza a alimentarse de carne de caballo. Al fin llega el ansiado convoy con dos mil acémilas cargadas de víveres pero, aunque creen algunos que estos durarán un año, lo cierto es que 4.000 soldados -otras tantas bocas más- han entrado con él en la ciudad, que se prepara para ser asaltada.

El enemigo abre brecha en tres lugares: Santa Lucía, Alemanes y San Cristóbal. No será fácil resistir ante el poderoso ejército francés. Lo intentan los militares y la población civil. Frailes, mujeres -sobre todo las del batallón de Santa Bárbara, al que pertenecía la señora Sumta, ama de llaves del médico 5 -y niños ayudan en los preparativos. Pero el 15 de septiembre el gobernador ordena una atrevida salida que envalentona a los invasores. Cuatro días después estos asaltan las murallas gerundenses por varios puntos.

Esa épica jornada del 19 es narrada con minuciosidad por Marijuán. La defensa de la ciudad se organiza con la participación de todos. Las casas se quedan vacías de enseres porque los muebles, colchones, trapos, calderos, etc. se utilizaban para obstaculizar el paso a las plazas del Aceite y del Vino. Mientras los militares protegían, al igual que Andrés, las partes de la muralla

5. El 3 de julio de 1809, Mateo Álvarez, el gobernador dio este nombre a la compañía femenina, formada por doscientos miembros y organizada en cuatro secciones. 
arruinadas como Santa Lucía, los frailes, monjas y hombres mayores ayudaban a transportar heridos, dándoles pan negro y algo de vino. Otras señoras, además, arrojaban grandes piedras al enemigo. También los chiquillos, sin temer al peligro, presenciaban la contienda como Badoret en San Cristobal y Manalet en Alemanes. Aquel día Gerona resistió.

Pero el 26 de septiembre llegaron refuerzos franceses que hicieron imposible cualquier tentativa de entrada o salida de la ciudad, que, sitiada y asediada, era ahora víctima del hambre y de las calenturas. En octubre ya no había nada que comer, ni harina, legumbres o carne. Se había acabado la de caballo y la de burro. Solo quedaban pececitos del río Oñá y pajaritos cazados en los tejados, pero a elevado precio. Los gerundenses se alimentan, entonces, de gatos.

Marijuán ve en la calle Ciudadanos y en la plaza del Vino a muchos enfermos sacados de los sótanos, víctimas del hambre y de las condiciones insalubres. También, muertos y heridos en el callejón de la Forsa. Como la catedral ya no podía contener a más afectados, estos ocupaban su larga gradería y la plaza. Pero, además, no quedaban medicinas.

Badoret, Manalet y sus amigos venden ratas, que sirven de alimento, en la plaza de las Coles, atrapadas en la casa abandonada del canónigo Ferragut, frontera a la suya. En la plaza del Vino han abierto una gran fosa en la que se entierra a los muertos. Al tiempo, el pequeño Gasparó, enfermo de fiebres, fallece. Y ese mismo día, pródigo en sucesos, Andrés cree que ha matado a don Pablo quien le había arrebatado una figura de azúcar para dársela como alimento a su hija. Además, es llamado a combatir con otros compañeros, muertos de hambre como él, en la muralla de Alemanes donde llega después de correr enloquecido por las calles. Es herido en el pecho. No mejorará hasta el 9 de diciembre en que le dicen que el bravo gobernador, muy enfermo, decide al fin rendirse. Al día siguiente se pactan unas condiciones, que no se cumplen, y los franceses entran en Gerona.

Ofrecen pan y vino a los enfermos y en las plazas de San Pedro y del Vino entran carros con víveres. Al ser destruida por una bomba la vivienda de los Mongat, Marijuán y Josefina, ya repuesta de su enfermedad, buscan a Siseta. Atraviesan el Oñar que divide la ciudad en dos barrios y, del Viejo, pasan al Mercadal. Cuando llegan al puente de San Francisco de Asís, Andrés ve a Badoret sobre un tejado de una de las casas colgadas del río, que dan la espalda a la plaza de las Coles y a la calle de la Argentería. Allí estaba también su hermana. Habían huido de Nomdedeu, quien, ya demente, quería comérselos.

6. Mantengo los topónimos, a veces mal transcritos, tal como parecen en el texto galdosiano 
Luego Marijuán lleva a Siseta y sus hermanos a otra vivienda en la calle de la Barca.

Los enclaves mencionados en la novela: plazas (del Aceite, del Vino, de la Catedral, de las Coles, de San Pedro), barrios (Viejo, Mercadal, Pedret, Montelivi, Pau -Palau-), calles (Cort-Real, de la Neu, Zapatería Vieja, de la Barca, Ciudadanos), torres de la muralla (Gironella, San Narciso, Alemanes, San Luis, Santa Lucía), edificios (castillos de Monjuich y Montagut, catedral de Santa María, iglesia de San Félix, santuario de los Ángeles), y ríos como el Oñar y el Galligants conforman un «marco geográfico [...] extraordinariamente fiable, cuyos nombres se mantienen todavía hoy» (Bastons i Vivanco, 2004: 48).

Es más, la ciudad que don Benito conoció en 1868, a decir de J. Ribas (1974: 151-152), conservaba casi íntegros las murallas, rehechas en sus desperfectos, que circunvalaban el casco antiguo, y los fuertes que los franceses habían dejado en pie. La fortaleza de Monjuich, aunque semivolada, aparecía todavía amenazante al contrario de la torre Gironella, reducida a escombros. Se entraba y salía en Gerona a través de las puertas de la muralla, nombradas en el episodio: la del Areny al sur, junto al cauce del Oñar, la de Mercadal, bordeando el río al oeste, la de Pedret o San Pedro, poco más allá del Galligants, al norte, y la de San Cristobal al este.

Todos estos espacios del entramado urbano gerundense que, como hemos visto antes, se relacionan con sucesos bélicos y la actividad desempeñada por los entes de ficción, son el escenario elegido por Galdós para situar la trama del séptimo episodio de la primera serie. Y, aunque Gerona no era una gran urbe como el Paris balzaquiano o el Londres dickensiano y ni siquiera alcanzaba las dimensiones del Madrid que, más adelante, el escritor canario llevaría a sus novelas, no hay duda de que siguió el plano o croquis de la ciudad -el que le hizo Almeda y él que él dibujó, seguido del nombre de los personajes ${ }^{7}-$ para elaborar este episodio. Pero no solo eso, lo tuvo en cuenta para presentar un trazado legible en conexión con otro aspecto estrechamente vinculado con la creación de la geografía urbana: el del movimiento de los personajes, que «contribuye a dar la impresión de existir en el texto una realidad «palpable»» (López-Landy, 1979: 23).

Esos desplazamientos de las criaturas ficticias por los diferentes lugares del mapa urbano de Gerona, además de crear el espacio novelesco, proporcionan una evidente sensación de dinamismo. Me refiero, evidentemente, a las idas y venidas de Marijuán desde las localizaciones militares en que está destacado en diversos puntos de la muralla -la Torre Gironella, la Torre de

7. Lo reproducen Pla i Dalmau (1994: 41) y Bastons i Vivanco (2004: 58).

Anales, 24, 2012, pp. 163-180 
San Narciso, junto al barranco de Galligans, Santa Lucía, el Condestable, Alemanes - a la casa de los Mongat en la calle de Cort- Real, situada en el barrio Viejo, y viceversa. También, las correrías, sin éxito, por este con Josefina para buscar a Siseta y los chicos, lo que les lleva a ir al barrio de Mercadal, al otro lado del Oñar.

Pero, incluso, los niños peregrinan por distintos puntos de la ciudad con una especial atracción hacia los que son escenario del combate. Manalet va a Santa Lucía, pero antes había estado en San Cristobal donde le habían agujereado su barretina con tres balazos, y Badoret, acompañado de Gasparó, en Alemanes tirando piedras a los franceses. Los tres juntos han buscado algo de comer entre los desperdicios acumulados en la calle del Lobo. Camino del Calvario, acompañados por otros chiquillos, han vitoreado al gobernador. Badoret, que se había metido en el convento de las Capuchinas, se encuentra con Andrés en Santa Lucía. Viene muy contento, cargando a Gasparó y seguido de otros niños, porque había conseguido unas guindas gracias a cumplir una misión en Alemanes.

De la casa del canónigo van a la plaza de las Coles para, como antes se apuntó, vender ratas. En esa vivienda destruida por un proyectil los busca Andrés cuando es atacado por un ejército de roedores, que también quieren comida, capitaneados por el más grande, Napoleón. Es un pasaje simbólico e irónico del que se ha hecho eco la crítica, metáfora de la batalla real, y denigratorio para los invasores franceses.

Badoret con su hermano muerto llega al lugar, próximo a Alemanes, donde Marijuán yace herido. No había querido echar el cadáver de Gasparó en la fosa de la plaza de las Coles. Cuando Andrés se recupera del balazo y de las fiebres que le habían aquejado, se dirige el 11 de diciembre, día siguiente a la entrada del enemigo en la ciudad, a la calle Cort-Real al encuentro de Siseta y sus hermanos. Al no hallarlos, se acerca a la de la Neu, donde se habían trasladado Nomdedeu y su hija, tras ser destruida su vivienda por una bomba.

Aparte del médico que es requerido en diferentes enclaves para atender a los heridos, Josefina, en principio guarecida en la casa por obligado encierro, se traslada hasta la Torre Gironella, según le dice su padre a Marijuán, vuelve un par de veces a la ciudad, es arrastrada hasta las murallas por las mujeres que llevaban pólvora, duerme dos noches al raso y la señora Sumta la encuentra en Alemanes. Luego, como se indicó más arriba, acompañará a Andrés en la búsqueda de los Mongat por el barrio Viejo preguntando de puerta en puerta, y por el de Mercadal.

Pero Gerona sugiere, además, esa sensación de movimiento no solo, como acabamos de ver, a través del ir y venir de sus personajes, sino del colectivo 
de los seres anónimos siempre presente en el espacio novelesco, que también contribuye a crear. Los heroicos militares en plena actividad bélica en los fuertes y en la muralla; los esforzados civiles ayudándoles con sus escopetas y yendo de un sitio para otro con pólvora, agua, ropa..., o transportando y asistiendo a los heridos, secundados por curas y monjas; la esperanzada masa que sale a recibir el convoy de alimentos y aclama al resistente gobernador siguiéndolo en sus recorridos de un lugar a otro.

Viene siendo habitual considerar la descripción como el procedimiento más frecuente para construir el espacio (Hamon, 1981), pues, en efecto, mediante ella, este «se consolida y adquiere su forma más definitiva y precisa» (Zubiaurre, 2000: 40). Así, la geografía urbana de la narrativa realista, que forma parte del espacio novelesco, es plasmada por el escritor canario, aunque no exclusivamente como se ha visto, con esa técnica, que E. Zola definía como «un estado del medio que determina y completa al hombre» (Bonet, 1988: 201). Si bien cabe puntualizar que en Gerona no existe, en líneas generales, una descripción minuciosa y extensa al modo naturalista ${ }^{8}$, lo que supondría, con respecto al tiempo de la novela, la existencia de pausas que detendrían el desarrollo de la acción y que, sin duda, limitarían la función narrativa que desempeña Andrés. Por el contrario, en este séptimo episodio de la primera serie la linealidad temporal sigue un ritmo rápido ocasionado por las múltiples síncopas lo que redunda en una impresión de dinamismo idéntica a la que proporciona el tratamiento del entramado urbano.

Únicamente Andresillo Marijuán configura un espacio estático en la presentación de tres inmuebles: la casa de los Mongat en la que se aloja, la del médico y la del canónigo Ferragut, y más que describir hace una enumeración de objetos. Por otro lado, es notoria la escasez descriptiva de plazas, calles o barrios (Bastons i Vivanco, 2004) y de los edificios de Gerona. Probablemente, dos circunstancias coincidan felizmente aquí para exculpar al autor canario. En primer lugar, no es descabellado pensar que don Benito no los recordaba con detalle cuando, años después de visitar la ciudad, escribe la novela. En segundo, parece posible que Andrés, honrado muchacho pero, al fin, aldeano poco cultivado no prestase especial atención a los monumentos gerundenses como lo haría un narrador culto. Por tanto, no resulta incoherente para el lector, dada la adecuación de la autobiografía a la subjetividad del yo, esa falta de interés por las construcciones religiosas y civiles que se observa en la novela.

8. Parece seguir Galdós en este punto la práctica de su admirado Dickens, de la que escribía en 1868: «un cuadro que aparece formado y compuesto de una sola pincelada [...] no le veréis detenerse [...] con la narración prolija de Balzac» (Shoemaker, 1972: 452-453). 
Sin embargo, Marijuán, reiteradamente, describe en su relato, aunque con grandes pinceladas lejos del pormenor, la geografía urbana cuando da datos o características de esta en aquella situación excepcional que sufre el espacio ciudadano. Son estampas colectivas que corresponden al sitio, iniciado el 6 de diciembre de 1809 en que muere, de resultas de las heridas del segundo cerco, el padre de los Mongat; a la resistencia hasta el 10 de diciembre; y a la capitulación desde esta fecha en que los enemigos entran en Gerona al amanecer del 11 hasta que Andrés se repone, tras unos pocos días, del percance sufrido y se presenta al capitán Satué para ponerse a sus órdenes como asistente.

Galdós atiende poco a los sucesos bélicos, aunque Marijuán combata como toda la tropa desde las murallas y piense que se trata de «batirse y no comer» (807). Su relato nos da, sin embargo, sin prolijidad alguna los efectos visibles, fruto de los ataques franceses y del justificado descuido de los gerundenses que han sustituido la vida cotidiana y normal de la ciudad por otra: «Ocupados todos en la defensa, nadie se cuidaba de los inmundos albañales que se formaban en las calles, ni de los escombros, entre cuyas piedras yacían olvidados cadáveres de hombres y animales» (807).

Pero con la llegada del ansiado convoy con los víveres, tan trabajosamente introducido en Gerona, la población revive. Tocan a llamada y la tropa corre a la muralla. Andrés lo describe:

tuvimos la indecible satisfacción de oír el vivo fuego de los franceses, atacados de improviso a retaguardia por las tropas de O'Donell y de Llauder. Para ayudar a los que venían a socorrernos se dispararon todas las piezas, se hizo un vivo fuego de fusilería desde todas las murallas, y por diversos puntos salimos a hostigar a los sitiadores, facilitando así la entrada del convoy. Por último, mientras hacia Bruñolas se empeñaba un recio combate en que los franceses llevaron la peor parte, por Salt penetraron rápidamente dos mil acémilas, custodiadas por cuatro mil hombres a las órdenes del general don Jaime García Conde. ¡Qué inmensa alegría! ¡Qué frenesí produjo en los habitantes de Gerona la llegada de socorro! Todo el pueblo salió a la calle al rayar el día para ver a las mulas, y si hubiesen sido seres inteligentes aquellos cuadrúpedos, no se les habría recibido con más cariñosas demostraciones, ni con tan generosa salva de aplausos (809).

El 19 de septiembre se produjo un gran ataque para romper el cerco y los sitiados respondieron con valentía. Andrés presenta con notable dinamismo el trasiego de la defensa conjunta:

Los soldados conservaban su actitud serena e imperturbable; pero en los paisanos se advertía una alucinación, una al modo de embriaguez, que no era natural antes del triunfo. Los frailes, echándose en grupos fuera de sus conventos, iban a pedir que se les señalase el puesto de mayor peligro; los señores graves de la ciudad, entre los cuales los había que databan del segundo tercio 
del siglo anterior, también discurrían de aquí para allí con sus escopetas de caza, y revelaban en sus animados semblantes la presuntuosa creencia de que ellos lo iban a hacer todo. Menos bulliciosos y más razonables que estos, los individuos de la Cruzada gerundense hacían todo lo posible para imitar en su reposada ecuanimidad a la tropa. Las damas del batallón de Santa Bárbara no se daban punto de reposo, anhelando probar con sus incansables idas y venidas que ellas eran el alma de la defensa; los chicos gritaban mucho, creyendo que de este modo se parecían a los hombres, y los viejos, muy viejos, que fueron eliminados de la defensa por el gobernador, movían la cabeza con incrédula y desdeñosa expresión, dando a entender que nada podría hacerse sin ellos (810).

Andresillo Marijuán sabe crear la atmósfera de frenética y anómala actividad en aquel día excepcional en que «la ciudad no era la ciudad de otros días» (810), ya que «la interrupción de lo ordinario era completa en toda la línea social, desde lo más alto a lo más bajo» (810). Así:

Las monjas abrían de par en par las puertas de sus conventos, rompiendo a un tiempo rejas y votos, y disponían para recoger heridos sus virginales celdas, jamás holladas por planta de varón, y algunas salían en falanges a la calle, presentándose al gobernador para ofrecerle sus servicios, una vez que el interés nacional había alterado pasajeramente los rigores del santo instituto. Dentro de las iglesias ardían mil velas delante de mil santos, pero no había oficios de ninguna clase, porque los sacerdotes, lo mismo que los sacristanes, estaban en la muralla. Toda la vida, en suma, desde lo religioso hasta lo doméstico, estaba alterada [...] Ninguna cocina humeaba, ningún molino molía, ningún taller funcionaba (810).

Andrés admira la organización de la defensa ciudadana, que don Mariano Álvarez llevaba a rajatabla y se extraña de que «no hubiera confusión en aquel desbordamiento espontáneo del civismo gerundense» (810). Desde que, «muy temprano» (811), comenzaron los bombardeos, las campanas tocaban a rebato para alertar del peligro, pero se ocupaban de este menester los chicos porque los campaneros se dedicaban a otros asuntos. Ese sonido inhabitual era acompañado por el de los tambores que «recorrían las calles, repicando su belicosa música» (811), a lo que se unía la extraña iluminación de «los resplandores de los fuegos parabólicos» (811) que cruzaban el cielo.

Ese 19 de septiembre el ímpetu colectivo es tanto en la prioritaria causa común que todo queda relegado:

ninguno se cuidaba de la casa que ardía, del techo desplomado, de los hogares a cada instante destruidos por el horrible bombardeo. Las madres llevaban consigo a los niños de pecho, dejándoles al abrigo de una tapia, o de un montón de escombros, mientras desempeñaban la comisión que el instituto de Santa Bárbara les encomendara (811). 
Marijuán estaba destacado en Santa Lucía, donde había mucha tropa y paisanos. Les hacen frente a los franceses, despreciando la muerte, al tiempo que el gobernador en primera línea descargaba sablazos contra los que intentaban subir. Todos estaban decididos a defender la ciudad no dejándoles entrar. Cualquier arma u objeto era utilizada para ello: «Si a tiros no lográbamos contenerles, les acuchillábamos sin compasión; y como esto no bastara, aún teníamos a la mano las mismas piedras de la muralla para arrojarlas sobre sus cabezas» (812-813), lo que hacían las mujeres con mucho denuedo.

No obstante, la fuerza del enemigo era muy grande:

Había que ver el empuje de aquellas columnas de cerdos [...] No parecían sino lobos hambrientos, cuyo objeto no era vencernos, sino comernos. Se arrojaban ciegos sobre la brecha, y allí de nosotros para taparla (812).

Cuando los franceses estaban a punto de desistir del asalto, Andrés describe el ambiente propio de una escena bélica:

No nos veíamos unos a otros, porque el polvo y el humo formaban densa atmósfera en toda la ciudad y sus alrededores, y el ruido que producían las doscientas piezas de los franceses vomitando fuego por diversos puntos, a ningún ruido de máquinas de la tierra ni de tempestades del cielo era comparable. La muralla estaba llena de muertos que pisábamos inhumanamente al ir de un lado para otro, y entre ellos algunas mujeres heroicas expiraban confundidas con los soldados y patriotas. La señora Sumta estaba ronca de tanto gritar, y don Pedro Nomdedeu, que había arrojado muchas piedras, tenía los dedos magullados; pero no por eso dejaba de cuidar a los heridos, ayudándole muchas señoras, algunas monjas y dos o tres frailes, que no valían para cargar un arma (813).

Al retirarse los atacantes, Marijuán y sus compañeros se sienten orgullosos por haber conseguido semejante resultado con tan pocos medios, teniendo en cuenta, además, su condición de sitiados: «Nosotros nos caíamos de hambre, ellos no carecían de nada; nosotros apenas podíamos manejar la artillería, ellos disparaban contra la plaza doscientas bocas de fuego» (814). Y será Manalet quien describa el regocijo por el triunfo en la calle Ciudadanos: «va el gobernador con mucha gente, muchas banderas; delante van las señoras cantando, y los frailes bailando, y el obispo riendo, y las monjas llorando» (816). Sin embargo, «incendiados varios edificios de la ciudad, esta ofrecía en su estrecho recinto frecuentes escenas de desolación y angustia» (822-823).

En vista del fracaso de la intentona, el enemigo decide cambiar de táctica: estrechar más el cerco de modo que, sin recursos, Gerona no tenga más remedio que rendirse. Marijuán da, entonces, nuevas notas descriptivas que presentan al lector un hábitat urbano inhóspito y triste, en el que el fantasma del hambre hace estragos: 
familias desvalidas, formando horrorosos grupos de desolación en medio de la vía pública, con los pies en el lodo y guarecida la cabeza del sol y la lluvia bajo miserables toldos de sucias esteras. Se arrancaban de las manos unos a otros la seca raíz de legumbre, el fétido pez del Oñá, las habas carcomidas y los huesos de animales no criados para la matanza (830-831).

Los soldados, a quienes se les daba una ración de trigo, ya no luchaban pero recibían bombas y granadas. Los civiles se alimentaban de gatos y perros. Además, diferentes dolencias físicas hacían mella en la población, protagonista ahora de la muerte, como bien atestigua Andrés:

En la calle Ciudadanos y en la plaza del Vino vi muchos enfermos que habían sido sacados de los sótanos para que murieran menos pronto. Su mal era de los que llamaban los médicos la fiebre nerviosa castrense, complicada con otras muchas dolencias, hijas de la insalubridad y del hambre; y en los de tropa todas estas molestias caían sobre la fiebre traumática (831).

Aquella desempeñaba diferentes labores socorriendo a los ciudadanos. Correspondía así a la ayuda que estos les habían prestado para evitar el asalto de los franceses. El ambiente de la topografía urbana que describe Marijuán no puede ser más lamentable:

aquí me llamaban para que ayudase a arrastrar a un enfermo, allí me rogaban que ayudara a poner tierra encima de los cadáveres [...] en la calle de la Zapatería Vieja sacamos fuera de los sótanos varios clérigos, ancianos y niños [...] La calle o callejón de la Forsa, que conduce desde la Zapatería Vieja a la catedral, era una horrible sentina, una acequia angosta y lóbrega, donde algunos seres humanos yacían como en sepultura esperando quien los socorriese o quien los matase. Entramos en ella [...] y recogimos los cuerpos vivos y medio vivos, muertos y medio muertos, sacándolos a las gradas de la catedral, donde les bañasen aires menos corrompidos. La catedral ya no podía contener más enfermos y la plaza se fue convirtiendo en hospital al descubierto (831).

En este enclave, que será aprovechado por Galdós como lugar escénico para situar en él el acto III de su drama Gerona, estrenado el 3 de febrero de 1893, aparecerá, entre los vítores de la multitud, don Mariano Álvarez dando en lo alto de la escalinata disposiciones para socorrer a los heridos. Será este acceso al edificio religioso el elegido por Andrés como síntesis metonímica de la desgraciada plaza sitiada:

La gradería ofrecía el más lamentable aspecto y con la algazara de los vivas y aclamaciones dirigidas al gobernador era difícil oír las quejas y lamentos [...] los cien escalones que conducen a la catedral ofrecían en pavoroso anfiteatro un cuadro completo de los males de la heroica ciudad (832).

Galdós introduce un nuevo asalto francés en el capítulo XIX cuando, muerto Gasparó, el más pequeño de los Mongat, «un extraordinario y vivísimo ruido 
exterior» (854) conmueve a toda Gerona: «Sonaban cajas, corría la gente, la trompeta y el tambor llamaban a todo los hombres al combate» (854). Andrés, con su fusil al hombro, corre por las calles, anda sin cesar, aunque casi no podía sostenerse. Se bate con desesperación, grita, se mueve y se comporta, como los demás, heroicamente hasta que cae herido.

Diferentes elipsis hacen progresar rápidamente el tiempo hasta el 9 de diciembre. Ya no se oyen cañonazos, y el silencio es percibido por Marijuán, que revive, como «un ruido indefinible» (857). El gobernador también ha caído enfermo. Gerona está a punto de rendirse porque la situación es insostenible: «enfermos o heridos los que aún vivíamos -dice Andrés-, con diez mil cadáveres esparcidos por las calles, alimentándonos de animales inmundos y sustancias que repugnaba nombrar» (859).

El día 10 se produce la capitulación a las siete de la tarde. El narrador aragonés, auténtico autor implícito, presenta el cumplimiento por parte de los soldados y vecinos de las clausulas estipuladas. Se adivina el desengaño de todos por la rendición y la altanería del que no ha sido derrotado:

inutilizaron las armas o las arrojaron al río, y al amanecer los que podían andar, que eran los menos, salieron por la puerta del Areny para depositar en el glacis unas cuantas armas si tal nombre merecían algunos centenares de herramientas viejas y fusiles despedazados. Los enfermos nos quedamos dentro de la plaza, y tuvimos el disgusto de ver entrar a los señores cerdos. Como no nos habían conquistado, sino simplemente sometido por la fuerza del hambre, nosotros les mirábamos de arriba abajo, pues éramos los verdaderos vencedores, y ellos a modo de impíos carceleros (860).

Cuando Marijuán recobra la salud, el paisaje urbano toma el aspecto propio de una ciudad devastada. Así lo relata:

No creáis que el andar por las calles de Gerona en aquellos días era cosa fácil, pues ninguna vía pública estaba libre de hoyos profundísimos, de montones de tierra y piedras, además de los miles de cadáveres insepultos que cubrían el suelo. En muchas partes los escombros de las casas destruidas obstruían la angosta calle, y era preciso trepar a gatas por las ruinas, exponiéndose a caer luego en las charcas que formaban las fétidas aguas remansadas (861).

La destrucción, la muerte, la angustia y el sufrimiento conforman el medio que acoge a los supervivientes después de un asedio de siete meses ${ }^{9}$. En diferentes puntos de la ciudad, «los franceses se ocupaban de tapar con tierra los hoyos donde habían sido arrojados los cadáveres, y miles de cuerpos desaparecían de la vista de los vivos para siempre» (865). Andrés y Josefina observan

9. Urey (1998) ha visto ecos de El cerco de Numancia, de Cervantes en el de la Gerona galdosiana. Y Quevedo García (2011) ha analizado su lucha contra el francés. 
desde un puente sobre el Oñar el doloroso ir y venir de los transeúntes que «vagaban sin cesar de un lado a otro y [...] buscaban personas queridas que el desorden de los últimos días había hecho desaparecer» (865). No solo eso, Marijuán señala plásticamente lo acuciante de aquella búsqueda:

Las fosas sobre las cuales se echaba tanta tierra iban poco a poco destruyendo los rostros que habrían podido guiar en sus exploraciones a padres, esposos e hijos, y la necesidad de enterrar pronto hacía que muchas familias se quedasen en completa ignorancia respecto a la suerte de los suyos (865).

Será en un recinto cerrado y derruido, la alucinante vivienda del canónigo Ferragut, donde Andrés muestre al lector la consecuencia más triste de la guerra: la muerte de los niños. Ve en distintas habitaciones

hasta una docena de chicos de ocho a doce años, en quienes reconocí a los amigos que acompañaban a Badoret y Manalet en todas sus correrías; pero el estado de aquellos infelices niños era atrozmente lastimoso y desconsolador. Algunos de ellos yacían muertos sobre el suelo, otros se arrastraban por la biblioteca sin poderse tener, uno estaba comiendo un libro y otro saboreaba el esparto de una estera [...] Algunos de sus camaradas lloraban, llamando a sus madres, y por todos lados el espectáculo de aquella desolación infantil contristaba mi alma [...] Para alguno de estos llegó tarde el remedio [la comida], y no hicimos con ellos otra operación que entregar sus cuerpos a las pobres madres que venían a recogerlos, después de haberlos buscado inútilmente por toda la ciudad (867).

En todos los fragmentos de Gerona que hemos venido examinando el espacio urbano presentado a través de la subjetividad de Andrés Marijuán, testigo y protagonista de la defensa y cerco de la ciudad, no es un mero locus producto de la simple mimesis galdosiana. Más allá del recuerdo, hay una creación artística del paisaje urbano gerundense de esos meses de 1809, nunca percibido por el escritor canario.

Galdós, como antes se indicó, utiliza, para elaborarlo, determinadas técnicas o recursos como los recorridos de los personajes de un lugar a otro, la descripción y ciertas enumeraciones. No carecen de sentido, por el contrario, como en toda novela, llevan aparejados una significación, esa «mirada semántica» de la que habla C. Bobes (1985). Es decir, la topografía galdosiana de la pequeña urbe catalana porta su particular propuesta hermenéutica (Greimas, 1976; Lotman, 1978) al margen de su estricta dimensión física o territorial.

Es clara la simbiosis entre espacio y personaje (Gullón, 1984) en relación a Marijuán que lo recibe a través de sus ojos y oídos. Pero, además, trasmitido en su relato, su estado de ánimo -optimista, decaído, angustioso, dolorido, pesimista- configura la significación de los lugares que transita. Se produce 
una clara dialéctica entre el yo protagonista y el particular entramado urbano durante los días del asedio, la resistencia y la capitulación de Gerona.

Galdós pone un especial énfasis en convertir a su personaje, su comportamiento valeroso, su dinamismo, su resistencia, su orgullo, en sinécdoque del colectivo de sus habitantes. Pero también el escritor canario convierte las calles, plazas, edificios, etc. gerundenses en metáfora del todo, del unánime de la ciudad, viva y doliente. Así, don Benito, abandonando el realismo genético, mera mimesis a través del recuerdo, al que parece aludir en su autobiografía, va componiendo un mapa urbano de más altos vuelos.

Don Benito, si atendemos a los fragmentos a que antes nos referimos, diseña el espacio cargándolo, en crescendo, de significaciones metafóricas y simbólicas. Así, el topos o lugar ciudadano en movimiento como metáfora de vitalidad ante el opresor y símbolo de la ciudad vedada. En su colectiva acción guerrera llevada a cabo por todos, sin excepción de género, clase social, profesión, etc., de no menos aliento, en que se abandona toda actividad común, como metáfora de la defensa y símbolo de la ciudad luchadora. En sus padecimientos por las penalidades y el hambre ${ }^{10}$ como metáfora de la resistencia, símbolo de la ciudad sitiada. En los cadáveres sobre las calles, en los heridos, en los enfermos y en los supervivientes alimentados de repugnantes alimañas, cuero, corcho o papel como metáfora de suprema resignación y símbolo de la ciudad moribunda, al límite de sus fuerzas. En el paisaje después de la última batalla y la subsiguiente capitulación con las casas derruidas, las aguas fétidas, los miles de cuerpos insepultos, los montones de tierra y piedras, y los hoyos profundos en la vía pública como metáfora de la destrucción y símbolo de la ciudad arrasada.

De este modo, a base de las descripciones plásticas y evocadoras del espacio urbano, amén de otros procedimientos, que nos da Marijuán, el escritor canario consigue un efecto de verismo que el lector asume con toda naturalidad. No se trata, como ya se dijo, de que Galdós siga, para ello, una mera correspondencia reproductiva del mapa topográfico de Gerona, sino que, sobrepasando los postulados del realismo genético, alcance una identificación espacio novelesco-lector en aras de un realismo intencional (Villanueva, 2004) $)^{11}$.

Y esto se hace evidente cuando aquel llega a comprender que esa visión del conjunto urbano, creado imaginativamente y preñado de sentido como

10. Escribe Casalduero (1961: 52): «en Gerona, la lucha contra el francés se convierte en una batalla de ratas; todos, hombres y animales, atormentados por el hambre».

11. Los postulados teóricos galdosianos sobre tal realismo han sido analizados por Villanueva (2011a y 2011b) 
hemos visto, adquiere el significado último de este séptimo episodio: la épica de la ciudad heroica, nunca vencida. Esas «maravillosas hazañas» (791) a que se refiere Gabriel Araceli son protagonizadas por Gerona, cuyo gobernador «había detenido durante siete meses frente a una ciudad indefensa a más de cuarenta mil hombres, mandados por los primeros generales de la época; que no había sentido ni asomo de abatimiento ante una expugnación horrorosa» (885).

\section{BIBLIOGRAFÍA}

Bastons i Vivanco, Carles, edición, prólogo y notas a B. Pérez Galdós, Gerona, Madrid, Castalia, Col. Castalia Didáctica, 2004.

Bobes NAVES, Carmen, Teoría y estética de la novela. Semiología de La Regenta, Madrid, Gredos, 1985.

BONET, Laureano, ed., É. Zola, El naturalismo, Barcelona, Ediciones Península, 1988.

CASAlduero, Joaquín, Vida y obra de Galdós (1843-1920), Madrid, Gredos, 1961. GONZÁlEZ FIOL, Enrique (El Bachiller Corchuelo), «Nuestros grandes prestigios: Benito Pérez Galdós. Conclusión de las confesiones de su vida y de su obra», Por esos mundos, 186 (1910), pp. 27-55.

GUllón, Ricardo, «La historia como materia novelable», Anales galdosianos, 5 (1970), pp. 23-55.

Gullón, Ricardo, Espacio y novela, Barcelona, Antoni Bosch, 1984.

Greimas, Algirdas Julius, Sémiotque et Sciencies Sociales, Paris, Seuil, 1976.

HAMON, Philippe, Introduction à l'analyse du descriptif, Paris, Hachette, 1981.

HinterhäUSER, Los Episodios Nacionales de Benito Pérez Galdós, Madrid, Gredos, 1963.

LÓPEZ-LANDy, Ricardo, El especio novelesco en la obra de Galdós, Madrid, Ediciones de Cultura Hispánica del Centro Iberoamericano de Cooperación, 1979.

Lotman, Yuri, La estructura del texto artístico, Madrid, Itsmo, 1978.

Miralles, Enrique, «Gerona, episodio y drama de Galdós, a la luz de diversos materiales bibliográficos», Anales galdosianos, s. n. (2001), pp. 189-202.

Montesinos, José F., Galdós, I, Madrid, Castalia, 1968.

PenAs, Ermitas, edición. y prólogo a B. Pérez Galdós, Episodios Nacionales. Segunda serie, II, Madrid, Fundación José Antonio de Castro, 2011.

PÉRez GAldós, Benito, Memorias de un desmemoriado, Madrid, Consejería de Educación/Visor Libros, 2004.

Pla i Dalmau, Joaquim, «Girona dibuixada per Galdós», Revista de Girona, 162 (1994), p. 41.

QueVEdo García, Francisco J., «El tratamiento galdosiano de la guerra en Gerona», en Y. Arencibia y R. M. ${ }^{a}$ Quintana (ed.), Galdós y la gran novela del siglo 
XIX. IX Congreso Internacional Galdosiano, Gran Canaria, Cabildo de Gran Canaria, 2011, pp. 690-697.

RiBAS, José M., «El episodio nacional Gerona, visto por un gerundense», Anales galdosianos, s. n. (1974), pp. 151-165.

SCHraibman, José, «Espacio histórico/Espacio literario en Gerona», The American Hispanist, 12 (1976), vol. II, pp. 4-7.

SHOEMAKer, William H. (ed.), Los artículos de Galdós en <La Nación>. 1865-1866, 1868, Madrid, Ínsula, 1972.

Troncoso, Dolores, edición y prólogo a B. Pérez Galdós, Gerona, en Episodios Nacionales. Primera serie. La guerra de la Independencia, Barcelona, Destino, 2005, pp. 785-896.

UREY, Diane F., «Nested Intertexts in Galdós's Gerona», en J. P. Browrlow y J. W. Kronik (ed.), Intertextual Pursuits. Literary Mediations in Modern Spanish Narrative, Lewisbry, Bucknell University Press, 1998, pp. 179-200.

Villanueva, Darío, Teorías del realismo literario, Madrid, Biblioteca Nueva, 2004.

VillanueVA, Darío, «Galdós: teoría comparada de la novela», en Y. Arencibia y R. M. ${ }^{a}$ Quintana (ed.), Galdós y la gran novela del siglo XIX. IX Congreso Internacional Galdosiano, Gran Canaria, Cabildo de Gtan Canaria, 2011a, pp. 20-44

Villanueva, Darío, «Tres teorías, tres realismos: Zola, Galdós, James», 1616. Anuario de Literatura Comparada, 1 (2011b), pp. 267-291.

Zubiaurre, M. ${ }^{a}$ Teresa, El espacio en la novela realista, México, D.F., Fondo de Cultura Económica, 2000.

Fecha de recepción: 19-12-2011

Fecha de aceptación: 15-05-2012 